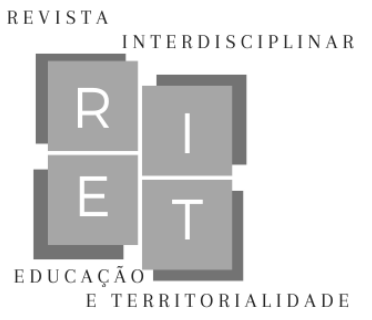

\title{
Desdobramentos da Pandemia Covid: 19 na educação formal: uma análise da unidade afeto-cognição
}

\author{
Unfolding the Covid Pandemic - 19 in formal education: an analysis of the \\ affection-cognition unit
}

\section{Desarrollar la Pandemia Covid - 19 en la educación formal: un análisis de la unidad afecto-cognición}

\begin{abstract}
Maria Eliza Mattosinho Bernardes
Programa de Pós-Graduação em Educação, Programa de Pós-graduação em Mudança Social e Participação Política, Universidade de São Paulo (USP)

São Paulo, São Paulo, Brasil

E-mail: memberna@usp.br

ORCID: https://orcid.org/0000-0003-4958-5647
\end{abstract}

Ana Paula Barbosa

Programa de Pós-Graduação em Educação, Universidade de São Paulo (USP)

São Paulo, São Paulo, Brasil

E-mail: anapaula.barbosa@usp.br

ORCID: https://orcid.org/0000-0001-9220-1843

Mara Aparecida de Castilho Lopes

Departamento de Ensino Básico, Instituto Nacional de Educação de Surdos (INES)

Rio de Janeiro, Rio de Janeiro, Brasil

E-mail: maralopes@alumni.usp.br

ORCID: https://orcid.org/0000-0001-5860-9810

Resumo: O objetivo deste estudo é analisar os desdobramentos da Covid -19 na educação formal e explicitar e condições necessárias para o desenvolvimento humano a partir das vivências de estudantes do ensino superior público no ano de 2020. O enfoque históricocultural fundamenta o estudo teórico e a análise das condições concretas evidenciadas durante o período no Brasil. Problematizam-se as contradições históricas na educação brasileira, a implantação do ensino remoto na escolarização, assim como são apresentados os princípios do sistema de ações conscientes na atividade pedagógica, considerados a base teórico-prática para o ensino promotor do desenvolvimento do psiquismo. No estudo de campo é analisado um relato, obtido na forma de levantamento, que representa o drama vivido pelos estudantes no primeiro semestre de 2020. A partir da análise teórico-prática, defendemos que para a promoção do desenvolvimento psíquico dos participantes há de se considerar a unidade afeto-cognição que contemple as necessidades objetivas e subjetivas dos sujeitos.

Palavras-chave: Atividade Pedagógica. Ensino Remoto. Afeto-cognição. 


\section{Desdobramentos da pandemia Covid - 19 na educação formal: uma análise da unidade afeto-cognição}

Abstract: The objective of this study is to analyze the consequences of Covid -19 in formal education and to explain the necessary conditions for human development from the experiences of public higher education students in 2020. The historical-cultural focus underlies the theoretical study and the analysis of the concrete conditions evidenced during the period in Brazil. The historical contradictions in Brazilian education are discussed, the implementation of remote teaching in schooling, as well as the principles of the system of conscious actions in pedagogical activity are presented, considered the theoretical-practical basis for teaching that promotes the development of the psyche. In the field study, a report is analyzed, obtained in the form of a survey, which represents the drama experienced by students in the first semester of 2020. From the theoretical-practical analysis, we deduce that, for the promotion of the participants' psychic development, there is to consider the affect-cognition unit that contemplates the objective and subjective needs of the subjects.

Keywords: Pedagogical Activity. Remote Teaching. Affection-cognition.

Resumen: El objetivo de este estudio es analizar las consecuencias del Covid -19 en la educación formal y explicar las condiciones necesarias para el desarrollo humano a partir de las experiencias de los estudiantes de educación superior pública en 2020. El enfoque histórico-cultural es la base para el estudio y análisis teórico de las condiciones concretas evidenciadas durante el período en Brasil. Se discuten las contradicciones históricas en la educación brasileña, la implementación de la enseñanza a distancia en la escolarización, así como se presentan los principios del sistema de acciones conscientes en la actividad pedagógica, considerada la base teórico-práctica de la enseñanza que promueve el desarrollo de la psique. En el estudio de campo se analiza un informe, obtenido en forma de encuesta, que representa el drama vivido por los estudiantes en el primer semestre de 2020. Del análisis teórico-práctico, se deduce que, para la promoción de la desarrollo psíquico de los participantes, hay que considerar la unidad afecto-cognición que contempla las necesidades objetivas y subjetivas de los sujetos.

Palabras clave: Actividad pedagógica. Enseñanza remota. Afecto-cognición.

Data de recebimento: $25 / 02 / 2021$

Data de aprovação: 10/06/2021

DOI: $10.30612 /$ riet.v\%vi\%i.13943

\section{Introdução}

Ao longo do ano de 2020, em virtude da crise sanitária causada pelo novo coronavírus SARS-CoV-2 (responsável pela doença Covid-19) no Brasil e no mundo, verificamos a necessidade de reorganização de ações nos processos educativos escolares e mudanças no uso de instrumentos pedagógicos utilizados na organização do ensino a partir da implantação do distanciamento social.

Agravada pelas condições sanitárias, constatam-se no campo da educação brasileira momentos tensos de indefinição de caminhos possíveis para superação das dificuldades enfrentadas em todas as instâncias educacionais, em especial a educação básica e pública que necessita de orientações objetivas para se reorganizar de forma efetiva. Trata-se de um 


\section{Desdobramentos da pandemia Covid - 19 na educação formal: uma análise da unidade afeto-cognição}

momento crítico na sociedade brasileira agravado pelas indefinições governamentais em virtude do negacionismo científico (ESCOBAR, 2021) que repercute em ações que exacerbam as contradições históricas da organização social vigente e da educação nacional.

Uma das evidências da dificuldade de acesso a orientações governamentais no campo da educação pode ser constatada no Ministério da Educação, local onde, pouca, ou nenhuma informação é encontrada sobre a Educação durante o primeiro ano da Pandemia da Covid 19. Outro agravante são as mudanças na organização do Ministério na Educação em plena crise social e sanitária, anunciada pela crítica social e institucional ao desgoverno atual. (ALVARENGA; PARREIRA, 2020). A fragilidade nos campos organizacional e epistemológico sobre as necessidades para uma Educação que seja a base para o desenvolvimento social e pessoal denunciam as inconsistências da governança atual para superar, emergencialmente, a situação social vivenciada no Brasil.

A situação social, emergente das condições concretas na realidade nacional e em crise de diferentes ordens, assola a sociedade brasileira fato que, segundo Santos (2020), requer mudanças estruturais e organizacionais. Incluímos neste rol de transformações a necessidade de uso de novos instrumentos pedagógicos e a implantação de novos modos de ação na organização do ensino (BERNARDES, 2009, 2010) em todos os níveis da educação formal.

A psicologia concreta, de raiz materialista, histórica e dialética (DEBORD, 2003; VIGOTSKI, 1996), que fundamenta este estudo considera que tais transformações de ordem social e pessoal é promovida pela mediação da cultura a partir das relações sociais que se objetivam em diferentes campos, sejam eles vinculados às particularidades da cotidianidade nos processos informais, mas fundamentalmente nas atividades organizadas de forma intencional e sistematizada, como o que ocorre na educação escolar em todos os seus níveis de objetivação.

Compreendemos que os processos educativos, considerando as adversidades sociais e materiais e as possibilidades de enfrentamento da crise, deveriam ser adaptados para ser possível a sua continuidade, apesar do distanciamento físico. Associações internacionais, como a UNESCO (United NationsEducational, Scientificand Cultural Organization) e a INEE - Inter-agency Network for Education in Emergencies, Theirworld- incentivam e mantêm programas de educação em situação de emergência (emergência provenientes de desastres sendo naturais ou não, como guerras e furacões, por exemplo), partindo do 


\title{
Desdobramentos da pandemia Covid - 19 na educação formal: uma análise da unidade afeto-cognição
}

princípio da educação como direito (INEE, 2006) e considerando que a educação é inserida no topo da lista das prioridades pelas famílias afetadas (UNESCO). A INEE esclarece que:

\begin{abstract}
A educação em situação de emergência, crises crônicas e durante os esforços de reconstrução tanto pode salvar vidas, como sustentar vidas. Pode salvar vidas, quer protegendo contra a exploração e agressão, quer disseminando mensagens-chave de sobrevivência em questões tais como segurança contra as minas terrestres ou a prevenção do HIV/SIDA. A Educação pode sustentar vidas oferecendo uma estrutura sólida, estabilidade e esperança no futuro durante tempos de crise, particularmente para crianças e adolescentes. (INEE, 2006, p. 5).
\end{abstract}

Tendo em vista as mudanças instituídas no campo educacional evidenciadas pela necessidade de transformação na situação social emergente da sociedade em crise, tem-se como objetivo analisar os desdobramentos da Covid -19 na educação formal e explicitar e condições necessárias para o desenvolvimento humano a partir das vivências de estudantes do ensino superior público no ano de 2020, a partir dos pressupostos do enfoque históricocultural (VIGOTSKI, 2001, LEONTIEV, 1983) no enfrentamento aos desdobramentos do distanciamento físico na educação formal.

No movimento de análise, enfatizamos a necessidade de manutenção de princípios essenciais para a formação e o desenvolvimento humano, ao dar ênfase à unidade afetocognição (VIGOTSKI, 2004) nos processos educativos. É problematizado, portanto, o modo instituído de objetivação das relações interpessoais na educação escolar (BERNARDES, 2009), visando o desenvolvimento das funções psíquicas superiores, enquanto a dimensão intrapessoal na formação humana, dando-se ênfase às condições concretas instituídas durante a Pandemia da Covid -19, no ano de 2020.

\section{Algumas contradições históricas na realidade educacional brasileira}

Diante da reorganização social provocada pelo distanciamento físico ao longo do ano de 2020, verificamos mudanças na prática social global, sobretudo nas ações pedagógicas na educação formal, em que todos os níveis educacionais foram amplamente impactados neste momento histórico. Algumas instituições de ensino se (re)organizaram no início do período de isolamento, em virtude de suas bases materiais serem favoráveis para alterar a dinâmica dos processos de ensino e aprendizagem presencial para o modelo remoto, principalmente instituições privadas, como revelou reportagens e estudos localizados como de Souza, Couto, Couto (2020) e da PPGED- UFSCAR (2020). Em contrapartida, outros 


\section{Desdobramentos da pandemia Covid - 19 na educação formal: uma análise da unidade afeto-cognição}

setores educacionais, principalmente a educação básica pública, assumem a condição de reféns de condições materiais e humanas limitadas pelas condições sociais e econômicas necessárias para a reorganizar as ações pedagógicas.

Uma das contradições identificadas é a situação emergencial de reestruturação das ações pedagógicas da forma presencial para a forma remota, sem que professores tivessem o domínio de ferramentas tecnológicas e metodologias relativas à docência no ensino não presencial. Trata-se de uma nova necessidade na organização da prática pedagógica a ser superada no momento pandêmico que requer aperfeiçoamento e domínio de tecnologias, fato nem sempre constatado na formação docente. Mill (2012), ao analisar o uso de tecnologias na educação, identifica alguns mitos no uso de tecnologia pelos professores como a contraposição e a tecnofobia, muitas vezes atribuindo às ferramentas tecnológicas maior valor do que o próprio processo pedagógico. Tal fato, de acordo com o autor, levaria à necessidade de inovações pedagógicas provocando insegurança e a necessidade de novas aprendizagens docentes. Estes mitos são contrapostos pelo autor, uma vez que a mediação tecnológica assume a perspectiva formal do processo pedagógico, sendo necessário que profissionais da educação, em todos os níveis de escolarização, tenham domínio do conhecimento específico e pedagógico visando a apropriação do conteúdo teórico pelos estudantes.

No texto Mudança de mentalidade sobre educação e tecnologia: inovações e possibilidades tecno pedagógicas, Mill (2012) problematiza o uso de tecnologias na educação ao fazer a analogia entre a tecnologia/semente e a educação/produto.

Há nas tecnologias, assim como na semente, diversos usos em potencial. O desafio é conhecer a maior quantidade possível de opções latentes nesta semente/tecnologia para lançar mão das melhores alternativas para busca de determinado objetivo. [...]. Todavia, é importante ter clareza das possibilidades que cada tecnologia/semente nos apresenta, pois a alimentação (para matar a fome imediata) pode ser mais urgente do que o cultivo da semente em alguns casos, embora em outros casos, à custa da vontade de comer temporariamente, o cultivo da semente leve-nos à produção de grãos suficientes para matar a fome de grupos maiores. (MILL, 2012, p. 36).

Diante da analogia apresentada, cabe-nos problematizar o uso da tecnologia/semente e da educação/produto no contexto social em análise e, ao mesmo tempo, vislumbrar aspectos essenciais no campo educacional que devem ser mantidos, ainda que os modos de ação possam ser transformados pelo uso de tecnologias diferenciadas. 


\section{Desdobramentos da pandemia Covid - 19 na educação formal: uma análise da unidade afeto-cognição}

A questão colocada em foco diz respeito à relação produto/educação e semente/tecnologia necessária para o desenvolvimento social e pessoal. Concebe-se, de acordo com o enfoque histórico-cultural, que pela mediação de signos e significações elaborados historicamente os elementos da cultura são apropriados pelos sujeitos, assim como pela mediação de instrumentos e ferramentas na forma de uso da tecnologia/semente criam-se campos de possibilidades para a objetivação dos processos educativos, para que tais as significações sejam apropriadas pelos sujeitos.

A realidade educacional vivenciada em 2020 no Brasil evidenciou as desigualdades sociais e econômicas instituídas na sociedade brasileira (STEVANIM, 2020; SILVA; GODOY, 2020); uma dessas objetivações é a diferença no acesso ao conhecimento teórico e científico pelos sujeitos em formação. No momento em que o acesso ao conhecimento a ser mediado nas escolas fica ainda mais dificultado pela mudança nas ferramentas e instrumentos utilizados nos modos de ação, agrava-se a crise educacional brasileira. Relacionamos tal fato à problematização feita por Mill (2012) sobre produto/semente e educação/tecnologia que precisam ser analisados de acordo com as (im)possibilidades instituídas na educação nacional e suas contradições. Questionamos, portanto: A quem pertence a semente? Quem pode usufruir da semente? Quem seria o agricultor a cultivar a semente para fornecer o alimento que mate a fome da população?

A complexidade presente em possíveis respostas aos questionamentos contempla o modo de organização societária nos campos econômico e político, assim como perpassa a especificidade epistemológica das áreas de conhecimentos, no caso a Educação e a Psicologia. Refere-se aos determinantes sociais historicamente instituídos evidenciados na espetacularização da sociedade capitalista. Contempla as condições concretas na sociedade contemporânea, as contradições históricas da educação formal no Brasil (MOURA, LIMA FILHO, SILVA, 2015), uma vez que as diferenças sociais e as condições materiais e culturais vinculam-se às lutas de classe e à manutenção do status quo.

Referimo-nos à condição social analisada por Guy Debord (2003, p. 13) quando afirma que "toda a vida das sociedades nas quais reinam as condições modernas de produção se anuncia como uma imensa acumulação de espetáculos." Segundo o autor, o espetáculo não se refere ao conjunto de imagens, mas às relações sociais decorrentes das mediatizações das imagens. Não se trata, portanto, do espetáculo como representação da realidade, mas trata-se da objetivação das contradições históricas que se perpetuam no processo de 


\section{Desdobramentos da pandemia Covid - 19 na educação formal: uma análise da unidade afeto-cognição}

alienação instituído na organização social há séculos. Segundo Debord (2003, p. 15), o espetáculo "[...] compreendido na sua totalidade, é simultaneamente o resultado e o projeto de produção existente. [...] constitui o modelo presente da vida socialmente dominante."

Portanto, as questões que envolvem a analogia entre semente/produto e tecnologia/educação vinculam-se aos determinantes sociais historicamente instituídos na sociedade brasileira e às políticas públicas educacionais que definem o campo de (im)possibilidades para que a educação escolar seja acessada pela sociedade de forma democrática e irrestrita.

Na analogia feita por Mill (2012), há de se saciar a fome da sociedade, mas também cuidar da semente para que todos possam ser supridos em suas necessidades básicas, no presente e no futuro. Em nossa análise, relacionamos a analogia em questão com a educação escolar de qualidade para que todos tenham a oportunidade para o desenvolvimento pessoal e social, assim como há de se contemplar e desenvolver as tecnologias para que todos possam ter acesso ao conhecimento teórico e científico a ser mediado na escola, para além do conhecimento local mediado na vida cotidiana.

Entendemos que tal fato vincule-se de estado de direito na sociedade democrática. Na Constituição Federal de 1988, em vigência no Brasil, consta no Capítulo III - Da Educação, da Cultura e do Desporto, na Seção I - Da educação que: "A educação, direito de todos e dever do Estado e da família, será promovida e incentivada com a colaboração da sociedade, visando ao pleno desenvolvimento da pessoa, seu preparo para o exercício da cidadania e sua qualificação para o trabalho." (BRASIL, 1988, Art. 205). Portanto, o compromisso do Estado com a educação assume protagonismo juntamente com a família; no entanto, em momentos de crises sociais, quando as famílias veem-se impossibilitadas de gerir as necessidades de seus filhos no uso de tecnologias que garantam o acesso à educação, esse protagonismo do Estado é necessário e desejado na definição de políticas públicas educacionais que garantam a educação para todos.

$\mathrm{Na}$ analogia feita por Mill (2012), o agente que organiza as ações educacionais na macroestrutura social assume a função de agricultor, criando as condições necessárias para que as sementes possam ser plantadas e germinadas; trata-se da função a ser exercida pelo Estado para que a Educação seja acessada por todos e promova o desenvolvimento pessoal e profissional, mediado pelas tecnologias necessárias para a sua objetivação na prática social global. No entanto, a contradição no uso de tecnologias nos processos educacionais, nos 


\section{Desdobramentos da pandemia Covid - 19 na educação formal: uma análise da unidade afeto-cognição}

diferentes níveis de escolarização no Brasil, precisa ser entendida como parte do projeto instituído na sociedade do espetáculo. Essa compreensão não exclui e não deve minimizar esforços para que a educação de qualidade se objetive como direito e seja uma conquista para todos.

Na educação nacional, relacionada à espetacularização da sociedade, objetiva-se pela política de Estado - "Educação para Todos" (BRASIL, 1996; 2001; 2008; UNESCO, 1994; 1998), que mantém o discurso oficial das políticas educacionais que aponta para a intencionalidade do rompimento dos processos de exclusão no interior da escola, no entanto, a prática social e as pesquisas realizadas na escola evidenciam a fragilidade e as contradições que emergem da realidade escolar brasileira. (BATISTÃO, 2013; PEREIRA, 2016; LOPES, 2017)

Apesar da reelaboração de políticas públicas educacionais e da pressão internacional pela universalização do ensino básico no Brasil, diversas ações transformadoras das práticas escolares ao longo dos anos permanecem camufladas por discursos inclusivos, que não conseguem se concretizar na prática social brasileira (MOURA, LIMA FILHO, SILVA, 2015). No momento de crise social, a exclusão social e educacional é colocada em evidência, no entanto, a raiz do processo exclusivo remonta à espetacularização da sociedade organizada nas bases do capitalismo.

Na trajetória da educação escolar brasileira, contradições acompanharam o discurso democrático na perspectiva inclusiva desde a sua origem, quando as classes sociais mais desfavorecidas conseguem acessar, mas nem sempre conseguem permanecer, no ambiente da escola - alterando o histórico de exclusão, que até então se dava pela via da reprovação. Entretanto, o movimento que se observou a seguir foi uma progressiva piora na qualidade do ensino público, enquanto a privatização do ensino atingia diferentes níveis de oferta conferindo um tom de mercadoria para o ensino e de empresa para a escola (SAMPAIO, 1998; BUENO, 2001).

Posteriormente, algo semelhante se deu em relação às pessoas com deficiência, após o movimento internacional conhecido como mainstreaming influenciar mundialmente sua forma de educação escolar. Seguindo os pressupostos da Declaração de Salamanca (UNESCO, 1994) para a construção de uma escola para todos, estudantes que recebiam atendimento educacional exclusivamente em instituições e escolas especializadas começaram a migrar para a escola regular em número cada vez maior. 


\section{Desdobramentos da pandemia Covid - 19 na educação formal: uma análise da unidade afeto-cognição}

A escola, por sua vez, objetiva-se a partir das dificuldades para atender a diversidade dos estudantes que se encontravam sob sua responsabilidade - delegando aos próprios estudantes e à suas famílias a culpa pelo seu sucesso ou fracasso escolar (TANAMACHI; MEIRA, 2003; GUZZO, 2010). Nesse contexto, também os estudantes com deficiência recebidos nesse espaço formativo conquistaram o direito de acessar as escolas mais próximas de suas residências, mas não o conhecimento sistematizado (SAVIANI, 2013). Por fim, alguns acabaram retornando aos institutos especializados dos quais saíram, frente à constatação das diversas contradições que compõem a realidade da escola que se denomina inclusiva.

Consideramos que as mudanças instituídas nas últimas décadas na educação brasileira são o produto do movimento de reivindicação de grupos sociais que buscam fazer valer seus direitos e interesses diante das possibilidades de uma sociedade democrática; no entanto, a lógica que permeia as mudanças na educação escolar não promovem transformações no modo excludente próprio da sociedade capitalista. A alteração na lógica da exclusão social pela via da educação escolar mantém-se diante de mudanças no modo de organização das políticas educacionais, não garantindo efetivamente a educação de qualidade para todos, necessária para viabilizar a inclusão social.

As contradições históricas enraizadas na educação escolar brasileira são o produto da objetivação de políticas públicas educacionais - nos níveis federal, estadual e municipal - que veem a escola como uma instituição para a manutenção do poder e manutenção das diferenças sociais. Mészáros (2008) ressalta que a educação faz parte da construção do poder ideológico do Estado e, portanto, há de se cuidar para que as instituições formais da educação não recaiam sobre a égide da reprodução dos interesses do capital presentes na organização social vigente. Na mesma direção, Ivo Tonet (2014) e Sérgio Lessa (2008) identificam a escola regular como campo de perpetuação do poder hegemônico instituído na sociedade capitalista, fato que cria entraves para a efetiva emancipação humana necessária para o desenvolvimento pessoal e social. Demerval Saviani (2013), Newton Duarte (2013), José Carlos Libâneo (2015) entre outros reconhecem que a escola seja um campo de intervenção do poder instituído visando sua manutenção, mas consideram a escola pública como instituição necessária e indispensável para a emancipação humana.

Diante das condições concretas e reais instituídas historicamente na educação escolar brasileira, a crise educacional no ano de 2020 torna-se ainda mais evidente, com 


\section{Desdobramentos da pandemia Covid - 19 na educação formal: uma análise da unidade afeto-cognição}

repercussões em todo o território nacional. Cardoso, Ferreira e Barbosa (2020) analisam as desigualdades no acesso à educação nas instituições públicas e privadas em diferentes níveis de escolarização e, diante dos fatos analisados, ponderamos sobre a importância da atuação de professores mobilizados ao trabalho docente que seja promotor do desenvolvimento dos estudantes. Os fatos concretos nos levam a considerar ser necessário evidenciar fundamentos teórico-metodológicos essenciais para garantir uma educação de qualidade que seja promotora do desenvolvimento humano, independentemente das tecnologias utilizadas para que o ensino seja objetivado, de modo presencial ou remoto.

Tais fundamentos vinculam-se aos pressupostos do enfoque histórico-cultural que preconizam a necessidade de mediação da cultura elaborada historicamente (HELLER, 2008) para que o desenvolvimento humano se objetive em cada sujeito singular. $\mathrm{Na}$ particularidade da educação escolar e pública, a mediação da cultura presente nos conteúdos específicos - ciência, da arte, da filosofia, da ética - visa a aprendizagem do conhecimento teórico-científico socialmente necessário para que todas as crianças, jovens e adultos tenham a oportunidade ao pleno (ou das máximas possibilidades) desenvolvimento da consciência e da personalidade, emancipando-se.

Para tanto, abordaremos a perspectiva teórico-metodológica que se vincula à concepção de homem entendido como ser social, ainda que sua base material esteja sob a égide da plasticidade orgânica constituída ao longo da histórica da espécie humana. Por isso, não serão abordadas as concepções naturalizantes ou adaptacionistas do psiquismo humano, uma vez que se concebe que a formação e o desenvolvimento humano não estão mais na dependência de leis biológicas, mas vinculam-se a leis sócio-históricas, conforme afirmam Vigotski, Luria e Leontiev.

\section{Mediação da cultura e a organização do ensino}

Um dos fundamentos da educação, entendida como atividade humana geral necessária para a humanização dos sujeitos (MARX; ENGELS, 2009) é a mediação da cultura por meio das relações sociais visando o desenvolvimento das funções psíquicas superiores, conforme afirma Vigotski (1996). Tal compreensão subjaz aos princípios do materialismo histórico e dialético como raiz teórico-metodológica do enfoque históricocultural. 


\title{
Desdobramentos da pandemia Covid - 19 na educação formal: uma análise da unidade afeto-cognição
}

No processo de explicação sobre o desenvolvimento psíquico, Vigotski fundamentase na investigação sobre pensamento e linguagem/fala que se articulam como unidade nos processos mediadores por meio de instrumentos e signos. $\mathrm{O}$ autor propõe teses sobre o desenvolvimento da linguagem que, segundo Elkonin (1996), continuam atuais. Sejam elas:

\begin{abstract}
Para explicar o desenvolvimento psíquico, Vygotsky usa o desenvolvimento da linguagem. Ao analisar o desenvolvimento da linguagem nesse período, ele propõe duas teses, que não perderam o sentido até os dias de hoje. Em primeiro lugar, a tese de que o desenvolvimento da linguagem [...] não pode ser analisado fora do contexto, fora da comunicação da criança com os adultos e da interação com as formas 'ideais' de comunicação verbal, ou seja, fora da linguagem dos adultos, na qual a própria linguagem da criança se confunde; em segundo lugar, a tese de que 'toda a parte sonora da linguagem infantil se desenvolve na dependência direta do aspecto semântico da linguagem infantil, ou seja, está subordinada a ele' (ibid.). É claro que não é possível analisar o desenvolvimento dos processos psíquicos fora do desenvolvimento da linguagem, nem, junto com isso, explicar o desenvolvimento da percepção apenas pelas conquistas da criança na esfera da linguagem, deixando de lado o domínio prático real dos objetos humanos pela criança. (ELKONIN, 1996, p. 409-410).
\end{abstract}

As teses anunciadas evidenciam a importância dos processos de comunicação e mediação das significações produzidas historicamente pela cultura, assim como ressaltam a importância de ações práticas com objetos reais para que o sistema funcional psíquico se constitua e se desenvolva. Trata-se de leis gerais sobre a formação do psiquismo humano que, no nosso entendimento, vinculam-se a todos os sujeitos humanos, não se restringindo ao problema do desenvolvimento da criança na relação com os adultos pelos processos de comunicação.

Nas investigações sobre a formação e desenvolvimento de crianças, jovens e adultos realizadas no GEPESPP/LEDEP ${ }^{1}$ temos constatado que as leis do desenvolvimento da linguagem são generalizáveis, uma vez que podem ser a base para a análise do pensamento e da linguagem em diferentes idades. As significações e os instrumentos são colocados à luz dos processos de desenvolvimento psíquico por Vigotski, identificando-os como mediadores da produção humana material e não material, ou seja, são elementos essenciais na mediação

\footnotetext{
${ }^{1}$ GEPESPP-LEDEP - Grupo de Estudo e Pesquisa em Educação, Sociedade e Políticas Públicas: concepções da teoria histórico-cultural / Laboratório de Educação e Desenvolvimento Humano (Universidade de São Paulo)
} 


\section{Desdobramentos da pandemia Covid - 19 na educação formal: uma análise da unidade afeto-cognição}

da cultura produzida historicamente pelo conjunto dos homens, humanizando-os pelos processos educativos em geral.

Segundo Vigotski (2001), para que o desenvolvimento do psiquismo humano seja objetivado são necessários processos educativos devidamente organizados com a finalidade de criar condições favoráveis para a apropriações teórico-práticas, entendidas como produções culturais, por parte dos sujeitos envolvidos no processo. No processo de mediação das significações e objetos reais, devem ser criadas ações colaborativas para que os sujeitos superem as manifestações do desenvolvimento atual - o que se consegue fazer sozinho - até que haja manifestações de aprendizagem com maior complexidade, de forma correta e individual. Este campo de possibilidades entre o que se faz sozinho e o que pode vir a ser feito em situação colaborativa e, posteriormente, de forma individualizada, é identificado na psicologia histórico-cultural como Zona de Desenvolvimento Proximal - ZDP. Segundo Vigotski (1996, p. 269), "a esfera dos processos imaturos, porém em via de maturação, configura a zona de desenvolvimento proximal da criança". Sobre o conceito, Beatón (2005, p. 232) afirma que:

A ZDP é um conceito abstrato que pretende explicar um processo ideal, subjetivo, cujos únicos indicadores objetivos, são os resultados do que o sujeito não podia fazer anteriormente e que mais tarde realiza de forma independente, os tipos de ajuda que se brindam ao sujeito e as respostas aos diferentes tipos de ajuda. Sem dúvida, em função disso é de supor que este processo implica um tempo e um espaço, para a acumulação de conhecimento e conteúdos e a formação de novas estruturas de desenvolvimento.

O conceito de ZDP é considerado de grande importância para os processos educativos, especialmente no âmbito da educação formal, uma vez que é no campo de possibilidades de desenvolvimento que o ensino devidamente organizado deve intervir com a finalidade de promover a superação das manifestações do desenvolvimento atual pela via de situações colaborativas, nas relações interpessoais, para que seja possível a realização das ações mais complexas por parte dos sujeitos de forma independente. Trata-se de ações interpessoais para a transformação e desenvolvimento intrapessoal.

Os processos educativos objetivam-se em várias esferas da prática social global, porém sempre como a finalidade de humanização dos herdeiros da cultura. Sua objetivação ocorre por meio da educação informal viabilizada no âmbito da família e das relações cotidianas, da educação não-formal que se realiza em grupos diversos com a 


\section{Desdobramentos da pandemia Covid - 19 na educação formal: uma análise da unidade afeto-cognição}

intencionalidade de promover a aprendizagem e o desenvolvimento dos indivíduos, ou pela educação formal organizada de forma sistematizada e definida pelas políticas educacionais em todos os níveis de escolarização. A educação, portanto, é entendida como a forma de organização de ações sociais que criam possibilidades para a mediação dos elementos da cultura material e não material, a partir das relações sociais, humanizando o próprio sujeito humano (MARX; ENGELS, 2009).

Em todos os processos educativos há de se considerar as condições concretas e reais nas relações sociais definidas ontologicamente na organização societária que criam possibilidades, mais ou menos favoráveis, para o desenvolvimento humano. Uma vez que se entenda que é pela apropriação dos elementos da cultura que ocorre o desenvolvimento psíquico, há de se protagonizar os processos educativos para que ocorram o desenvolvimento dos indivíduos e da própria sociedade.

Leontiev (1983), ao elaborar a teoria da atividade, a identifica como o conjunto de ações que transforma o próprio sujeito humano e a realidade externa à ele, por meio de ações conscientes. Trata-se, conforme afirma o próprio autor, da unidade molar composta por necessidade/motivo - objeto/objetivo - ação/operação - finalidade/condições concretas. De acordo com o autor, para que a atividade se objetive na prática social o objeto/objetivo da atividade deve relacionar-se diretamente à finalidade da atividade por meio de ações/operações vinculadas às condições concretas de existência. No caso da atividade que se objetiva no âmbito da educação formal, o ensino devidamente organizado e o estudo que visa a aprendizagem consciente são considerados unidade que visa o desenvolvimento omnilateral dos sujeitos. Nos nossos estudos teórico-práticos realizados no contexto escolar, atribuímos à unidade entre a atividade de ensino do professor e a atividade de estudo dos estudantes o conceito de atividade pedagógica (BERNARDES, 2009). Nestas condições, a unidade entre a atividade do professor e do estudante assume características da atividade humana consciente - práxis- que se diferencia da prática espontânea, aquela cuja finalidade não corresponda ao objetivo da atividade.

A atividade pedagógica, portanto, é concebida como uma atividade orientada a fim o desenvolvimento omnilateral dos sujeitos que a integram e a produção de processos educativos formais no âmbito escolar. Conforme Bernardes (2012), trata-se da dupla objetivação da atividade pedagógica que assume a condição particular da práxis revolucionária (VÁZQUEZ, 1977). A atividade pedagógica entendida como práxis, 


\section{Desdobramentos da pandemia Covid - 19 na educação formal: uma análise da unidade afeto-cognição}

portanto, é coletiva e transformadora das relações sociais orientadas para o ensino devidamente organizado e para a aprendizagem promotora de desenvolvimento dos sujeitos em atividade. Enquanto unidade, a atividade pedagógica integra um sistema de ações e operações que articulam de forma consciente, ações objetivas no campo das condutas cooperativas e colaborativas entre os sujeitos em atividade; no campo do objeto real de estudo enquanto produção historicamente elaborada que assume condição ideal e material na realidade concreta; no campo do conhecimento teórico-prático que fundamenta a formação integral e a execução de ações pedagógicas por parte dos sujeitos em atividade. $\mathrm{O}$ esquema a seguir sintetiza o sistema de ações conscientes na atividade pedagógica.

Figura 1 - Sistema de ações conscientes na atividade pedagógica

\section{CONHECIMENTO TEÓRICO-PRÁTICO}

Formação da consciência do professor e dos estudantes

OBJETO REAL DE ESTUDO

Material ou ideal - produção histórica

\section{CONDUTA COLABORATIVA}

Respeitosa às diferenças, afetiva e de ajuda - ZDP

Ressalta-se que, para que o sistema de ações conscientes na atividade pedagógica se objetive enquanto unidade, é necessário a formação profissional que desenvolva a consciência do professor sobre: a) sua função social na sociedade de classes, b) sobre a importância do ensino devidamente organizado como finalidade de promover $\mathrm{o}$ desenvolvimento das funções psíquicas, uma vez que que o mesmo não ocorre de forma espontânea ou natural, c) das relações sociais fundamentadas em processos colaborativos e coletivos com situações respeitosas e afetivas, assim como de ajuda recíproca para superar dificuldades momentâneas tanto de ensino quanto de aprendizagem, d) da relevância da historicidade do objeto real de estudo - material ou não material - enquanto direito de todos ao acesso à produção humana. Assim como a consciência do professor sobre tais aspectos é constituída em sua formação, a conduta consciente do professor no exercício de sua função social é fundamental para a formação/transformação da consciência dos estudantes sobre sua própria função social na sociedade e da importância de se apropriar do conhecimento teóricoprático visando seu desenvolvimento e, possivelmente, sua emancipação enquanto sujeito ativo na sociedade de classes. Corresponde ao princípio marxiano sobre a formação da 


\section{Desdobramentos da pandemia Covid - 19 na educação formal: uma análise da unidade afeto-cognição}

consciência entendendo-a como síntese criativa das vivências na socialidade, e não o seu inverso.

A objetivação do sistema de ações conscientes na atividade pedagógica assume a dialeticidade necessária para que todos os sujeitos em atividade se transformem, se desenvolvam, assim como transformem sua prática social e a própria sociedade. Nestas condições, o sistema na atividade pedagógica assume o que Vázquez (1977) identifica como práxis revolucionária uma vez que: "a) não só os homens são produto das circunstâncias, como estas são igualmente produto seus. [...]; b) os educadores também devem ser educados; c) as circunstâncias que modificam o homem são, ao mesmo tempo, modificadas por ele [...]" (p. 159-160).

A complexidade na organização do ensino em diferentes níveis de escolarização pautado no sistema de ações e operações na atividade pedagógica requer que professores tenham domínio de conhecimentos nos campos da didática, da psicologia da educação, de metodologias de ensino, de políticas públicas educacionais e de outros da pedagogia, assim como tenha domínio do conhecimento epistêmico da área em que atua (alfabetização, matemática, ciências da natureza, língua portuguesa ou estrangeira etc.).

Os pressupostos do ensino devidamente organizado e promotor do desenvolvimento do psiquismo e da emancipação humana são passíveis de generalização e, no nosso entendimento, devem ser contemplados em todas as etapas de formação. Em momentos de crise, como no ano de 2020, o distanciamento físico provocado pela pandemia da Covid-19 expõe a necessidade de mudanças formais na organização das ações práticas, utilizando-se de ferramentas que viabilizassem as relações interpessoais, expõe a necessidade de pensar no sistema de ações e operações que contemple a semente/tecnologia e o produto/educação, conforme a analogia elaborada por Mill (2012). No entanto, os fundamentos do ensino devidamente organizado e explicitados no sistema de ações e operações na atividade pedagógica são considerados generalizáveis, necessários e relevantes para a concretização de prática social educativa e transformadora das dimensões internas e externas aos sujeitos em atividade.

Ainda que as mudanças na organização do ensino sejam aparentes (do modo presencial para o remoto), ou seja, no campo formal, identificamos que o uso de recursos tecnológicos que propiciem a comunicação frente à necessidade do distanciamento físico tem repercussões diferentes nos diversos níveis de escolarização. Em todos os níveis de 


\section{Desdobramentos da pandemia Covid - 19 na educação formal: uma análise da unidade afeto-cognição}

escolarização o sistema de ações e operações na atividade pedagógica é insubstituível nos processos educativos que sejam mobilizadores de desenvolvimento psíquico. No entanto, para que de fato a organização do ensino promova o desenvolvimento psíquico dos sujeitos há de se priorizar a qualidade do processo de ensino e aprendizagem, a efetividade da comunicação do conhecimento elaborado historicamente, a colaboração e a unidade afetocognição entre os integrantes de forma respeitosa às diferenças individuais, independentemente da via de execução dos processos educativos, seja ela presencial ou remota.

Trata-se de valorizar, no sistema de ações e operações na atividade pedagógica (BERNARDES, 2012), as relações interpessoais que integram os aspectos afetivos, volitivos e cognitivos enquanto unidade. Ressaltamos, portanto, como condições necessárias para que o ensino promova o desenvolvimento do psiquismo dos sujeitos, a mediação do conhecimento elaborado historicamente, a valorização das relações interpessoais como objetivações da unidade afetiva-cognitiva, e o uso de instrumentos que proporcionem condições materiais e não materiais adequadas no momento de transformação das práticas instituídas nos processos de ensino e aprendizagem. Cabe-nos, portanto, evidenciar a constituição da unidade interfuncional do psiquismo humano a partir das condições objetivadas pela e na atividade pedagógica.

\section{Unidade afeto-cognição na atividade pedagógica}

Uma das teses da psicologia histórico-cultural é a concepção de unidade interfuncional do psiquismo humano, que segundo Vigotski (1996; 2001), deve ser entendida não como soma de partes, fragmentadas e complementares, mas como totalidade indivisível que, ao produzir e acessar elementos da cultura, transforma-se na sua integralidade, enquanto unidade do psiquismo humano. Assim, os diversos aspectos do psiquismo humano como pensamento, linguagem, memória, percepção, abstração, emoção e razão entre outros, são entendidos em sua totalidade, como unidade interfuncional indivisível.

Neste sentido não se pode deixar de considerar que a transformação de funções primárias, também presentes nos demais animais, em funções superiores, as especificamente humanas, não ocorre de forma natural decorrente dos processos de maturação orgânica, conforme afirmam teorias psicológicas de raiz biologizante e naturalistas, mas como síntese da transformação da unidade interfuncional mediada pela apropriação da cultura elaborada 


\section{Desdobramentos da pandemia Covid - 19 na educação formal: uma análise da unidade afeto-cognição}

historicamente nas diversas relações sociais, em especial pela mediação do conhecimento teórico científico no contexto educacional.

A superação da concepção biologizante na constituição do psiquismo humano foi amplamente problematizada por Vigotski (1996) pelo exercício de crítica à psicologia tradicional. Um dos aspectos problematizados pelo autor no início século $\mathrm{XX}$, porém não sistematizado em virtude de sua morte precoce, é a temática da emoção / afeto. Por meio da crítica à Teoria Periférica, Vigotski (2004) desconstruiu, por meio da análise de publicações em pesquisas clínicas com animais e com humanos lesionados, a concepção de que as emoções são só sensoriais, relacionadas às sensações corporais. Concebe, o corpo e o psiquismo como um todo, em que as emoções podem ser geradas ou provocadas de maneira independente pelo psiquismo ou pelo corpo, mas são dialeticamente associados e formam uma única emoção. Enquanto no corpo são expressos o estado da consciência, no psiquismo é compreendido por sua qualidade, ou seja, “[...] é o único e mesmo acontecimento traduzida em duas línguas" (VIGOTSKY, 2004, p. 245, tradução nossa). Portanto, os afetos fazem parte do psiquismo, estão imbricados em todas as funções psicológicas superiores. Sobre tal questão, Vigotski (1997b, p. 268) afirma que "[...] é próprio das funções psicológicas superiores uma natureza intelectual diferente e uma natureza afetiva diferente. Tudo reside no fato de que o pensamento e o afeto representam partes de um todo único - a consciência humana". Assim, na singularidade do sujeito concreto integra-se às esferas cognitiva e afetiva na formação da consciência e da personalidade.

Para Vigotski (2006), vivência é a unidade entre o sujeito, a sua personalidade e a forma como ele apreendeu a sua relação com o meio. O meio, por si só, não representa uma vivência, pois depende de como cada sujeito vivenciou as situações sociais emergentes da realidade. Uma mesma situação pode ser vivenciada por diversos sujeitos de formas diferentes, pois dependerá de como cada um se constituiu até aquele momento, suas memórias, afetos, cognição e consciência de si e da realidade. Portanto, é por meio das vivências que cada sujeito se constitui, desenvolve os seus afetos, seus modos de pensar e agir, de forma singular.

A concepção vigotskiana de que a cognição e afetos são constituídos como unidade dialética nas vivências ao longo da vida tem desdobramentos na análise das contradições do momento atual. Para o autor, as situações de crise são promotoras de desenvolvimento em diferentes idades a partir das diversas situações sociais emergentes. No momento atual de 


\section{Desdobramentos da pandemia Covid - 19 na educação formal: uma análise da unidade afeto-cognição}

crise social e sanitária do COVID-19, as repercussões do drama vivenciado de forma singular pelos sujeitos concretos (POLITZER, 1998) impactam na constituição do psiquismo humano, afetando a todos em suas rotinas cotidianas. Trata-se de situações sociais de desenvolvimento que nos afetam nas esferas da cognição e da afetividade, assim como no modo como realizamos as atividades de forma consciente, a partir das necessidades emergenciais no campo da socialidade.

Leontiev (1983) explica que as emoções dependem em grande medida das vivências do sujeito e que as emoções indicam a relação entre as necessidades do sujeito e a possibilidade de êxito nas atividades as quais se integra.

A especificidade das emoções consiste em que elas refletem as relações entre motivos - necessidades - e a conquista ou possibilidade de realização exitosa da atividade do sujeito, que responde as mesmas. Além disso, não se trata do reflexo dessas relações, senão de seu reflexo diretamente sensível de suas vivências (LEONTIEV, 1983, p. 162 -163).

No campo da atividade pedagógica, que integra dialeticamente o ensino e o estudo para que haja a aprendizagem de todos, emoções e afetos, assim como pensamento e linguagem, entre outras funções superiores - têm implicações na formação de motivos eficazes (LEONTIEV, 1983) para que sujeitos estejam em atividade, executem ações que cumpram os objetivos que correspondam à finalidade da atividade. Trata-se da dimensão volitiva que se integra às dimensões afetiva e cognitiva.

Em qualquer tempo e em qualquer modelo de efetivação na prática social, a educação formal precisa levar em conta a integralidade na formação dos sujeitos para que a condição ativa seja o modo de ação de professores e estudantes nos processos de ensino e de aprendizagem.

Diante do distanciamento social vivenciado na crise sanitária e com a reorganização dos processos educativos do modo presencial para o remoto, a perspectiva de se considerar a integralidade do psiquismo no desenvolvimento torna-se ainda mais premente. $\mathrm{O}$ afeto, a cognição e a construção de motivos precisam estar no foco da organização dos processos educativos para que criem condições favoráveis para a apropriação de conhecimentos, visando o desenvolvimento integral do estudante.

De acordo com Vigotski, as dimensões cognitiva e afetiva possuem a mesma importância e se constituem dialeticamente. Afirma que “[...] em qualquer etapa do desenvolvimento do pensamento corresponde à sua etapa do desenvolvimento do afetivo". 


\section{Desdobramentos da pandemia Covid - 19 na educação formal: uma análise da unidade afeto-cognição}

(VIGOTSKI, 1997b, p. 268). Assim sendo, o foco de análise dos processos de formação e de desenvolvimento do psiquismo humano relaciona-se à dimensão ontológica, ou seja, à história do ser humano enquanto ser social integrado a seu tempo histórico. Dialeticamente, pensamento e afeto implicam-se reciprocamente, ainda que sejam funções específicas e que se inter-relacionam ao longo da vida. Vigotski (1997a, p.87) explica que "o fato de eu pensar coisas que estão fora de mim não altera nada nelas, enquanto penso que afetos, que os coloca em outras relações com meu intelecto e outras instâncias, altera muito minha vida psíquica". No campo da educação formal, pensar sobre os afetos que emanam das relações interpessoais entre estudantes e entre professores e estudantes pode interferir na organização das ações coletivas e individuais. Há de se valorizar, na seara dos afetos e cognição, conforme indica Bernardes (2012), a execução de ações colaborativas e coletivas no processo de ensino e aprendizagem, de forma a respeitar as diferenças individuais e promover a participação colaborativa de todos os integrantes.

Em síntese, Vigotski (2001, p. 16) explica:

Quem separou desde o início o pensamento do afeto fechou definitivamente para si mesmo o caminho para a explicação das causas do próprio pensamento, porque a análise determinista do pensamento pressupõe necessariamente a revelação dos motivos, necessidades, interesses, motivações e tendências motrizes do pensamento, que lhe orientam o movimento nesse ou naquele aspecto.

Diante das considerações teórico-metodológicas apresentadas buscamos, pela via da constatação da realidade concreta, identificar o impacto do momento pandêmico na formação de estudantes em um curso de licenciatura da Universidade de São Paulo. Para tanto, foi feito um levantamento ao final da disciplina de Psicologia da Educação com a finalidade de identificar os modos de ação na organização do ensino e as relações afetivas e cognitivas na superação das dificuldades enfrentadas pelos estudantes no primeiro semestre do ano de 2020.

\section{A realidade dos estudantes durante crise sanitária COVID-19- 1 sem. de 2020}

No início do primeiro semestre de 2020, o planejamento das ações pedagógicas na disciplina de graduação - Psicologia da Educação, em um dos cursos de licenciatura na USP, estava em vigência quando que, de forma inesperada, todos foram impactados com a necessidade de isolamento e distanciamento físico, conforme as orientações do Ministério 


\section{Desdobramentos da pandemia Covid - 19 na educação formal: uma análise da unidade afeto-cognição}

da Saúde. Com as determinações da Comissão de Graduação, tornou-se necessária a adequação dos modos de ação na atividade pedagógica na disciplina. Um dos primeiros encaminhamentos na reorganização do ensino foi uma reunião pelo Google Meet para a escuta coletiva - estudantes, monitoria e docente - visando definir caminhos para a execução dos novos modos de ação na organização do processo de ensino e aprendizagem.

Foram encaminhados os seguintes procedimentos: a) aulas síncronas pelo Google Meet, gravadas e disponibilizadas a todos os alunos matriculados na disciplina; b) avaliação flexibilizada composta por registros do estudo individual referente à bibliografia básica e complementar de cada aula (disponibilizada no Tidia 4.0) e entrega de síntese da aprendizagem conceitual em cada unidade didática - $O$ que aprendi na unidade didática?; c) flexibilidade na data de entrega da produção individual dos alunos.

A finalidade na disciplina, após as alterações na organização dos modos de ação, foi definida como sendo a manutenção da qualidade do ensino e da aprendizagem, contemplando a integralidade do psiquismo nos aspectos afetivo-cognitivo por parte de todos os participantes da atividade pedagógica em curso.

Para que tal finalidade se objetivasse na prática pedagógica foi criada uma rede de colaboração com todos os estudantes, com apoio da monitora PAE, por e-mail e pelo Tidia 4.0. Em todo o início de aula, foi inserido na rotina da turma a escuta das angústias vivenciadas pelos estudantes, pela docente e monitora. Esta prática aproximou de forma respeitosa os participantes da disciplina, ainda que fisicamente distantes, uma vez que todos estavam vivenciando situações dramáticas na vida concreta. Todos os participantes (alunos, docente e monitora) tinham a oportunidade de se apoiarem reciprocamente para a superação do drama vivido individual e coletivamente.

Posteriormente, a aula seguia de acordo com os objetivos pedagógicos estabelecidos em cada conteúdo específico, assumindo características dialógicas com participação dos estudantes. Os modos de ação no âmbito pedagógico seguiam os princípios anteriormente explicitados no sistema de ações e operações na atividade pedagógica, com reflexões coletivas visando suprir dúvidas e valorizar as considerações dos estudantes sobre o texto lido. Posteriormente, seguia-se para a aula expositiva dialogada com esclarecimentos sobre os conceitos teóricos, com uso de diferentes mídias, dependendo das necessidades do objeto de estudo. A forma colaborativa e dialógica assume o modo das ações nas relações interpessoais, afetando uns aos outros de forma positiva e respeitosa. 


\section{Desdobramentos da pandemia Covid - 19 na educação formal: uma análise da}

\section{unidade afeto-cognição}

É apresentado, a seguir, um relato de estudante participante na disciplina que evidenciou o processo vivido no primeiro semestre de 2020. O texto elaborado por uma estudante é produto da reflexão individual a partir da questão: Como foi cursar a disciplina Psicologia da Educação no ano de 2020? O relato selecionado é apresentado na íntegra e são destacados aspectos considerados a expressão do drama vivido pela estudante e evidências da importância de se contemplar a unidade afeto-cognição na organização do ensino e nos modos de ação na atividade pedagógica.

\section{O caso Kerol}

A matéria de Psicologia da Educação já parece ser muito complexa. Quando acrescenta educação parece que fica dez vezes mais complicada $e$ assustadora. Contudo, as primeiras aulas, ainda presenciais, foram simples de certa forma, com as explicações da professora todos os textos complicados ficavam cristalinos como água. Mas como nem tudo são flores, veio a pandemia para ceifar meu sonho de finalmente compreender, mesmo que pouco, a mente de uma criança e como ela se desenvolve. Mas como a esperança é a última que morre, tivemos a santa Internet e as maravilhosas plataformas online para dar continuidade às aulas.

Com todos os professores se adaptando e se organizando, achei que tudo daria certo, seria como na faculdade só que na minha casa. E então, mais um desafio, estudar em casa. Com o cachorro latindo, vizinhos tentando derrubar o prédio e uma tentação chamada televisão praticamente chamando meu nome, foi quase impossível eu conseguir seguir os cronogramas, infelizmente no começo fiquei presa ao ciclo vicioso do "só mais um episódio". Como se já não houvesse obstáculos suficientes, o wifi para de funcionar durante a aula ao vivo. Com o sono desregulado e o peso aumentando, fui atingida pela mini avalanche de matérias se acumulando, e mesmo tentando priorizar algumas, sempre sobrava pouco tempo para as outras, e a cada dia que se passava, mais vezes ao dia a palavra "trancar" aparecia no meio das minhas preocupações. E foi nesse clima de tensão e desespero, que a vontade de chorar só aumentava, que precisei tirar forças só Deus sabe de onde para não desistir e me esforçar para ler os textos da matéria de Psicologia da Educação.

Desde que entrei no curso percebi meu grande interesse pela educação, apesar de não querer seguir nessa área, resolvi aproveitar a oportunidade de aprender mais sobre, e sem dúvida, nesses três semestres que estou no curso, a matéria de Psicologia da Educação foi a mais difícil, em parte pela pandemia e também por realmente ser algo complexo!

A professora com suas explicações, sempre me salvando do mar de confusão que é XXXXXX e CCCCCC [autores estudados], foi uma pessoa fundamental, tenho certeza de que não só para mim, mas também para meus colegas, estes inclusive que sempre tinham um tempo para tirar minhas dúvidas sobre algum texto. Acho importante ressaltar que apesar de nunca ter tirado dúvidas com a monitora, era um conforto muito grande saber que se eu precisasse ela estaria lá. 


\section{Desdobramentos da pandemia Covid - 19 na educação formal: uma análise da}

\section{unidade afeto-cognição}

A complexidade dos textos foi realmente um desafio. Era preciso muita concentração para conseguir compreendê-los, e como se manter focada com seus pais te pedindo alguma coisa a cada dois minutos? A resposta é não dá, então o que nos resta é brigar com alguém por meia hora de paz. Depois de conseguir ler com mais atenção, todas aquelas palavras difíceis começam a fazer sentido, e percebi que alguns textos eram tão legais, enquanto outros, demorei dez minutos para entender só o primeiro parágrafo.

Por fim, depois de muito esforço e alguns pesadelos com um sueco chamado XXXXXX, percebi que o semestre está chegando ao fim finalmente, e me sinto triste por não ter aproveitado melhor as aulas de Psicologia da Educação, principalmente por não ter tido a oportunidade de ter aulas presenciais, que sem sombra de dúvida teriam tornado a disciplina melhor ainda e ainda mais proveitosa. Mas fico feliz em dizer que mesmo a distância pude aprender mais do que esperava, e por isso, com certeza só tenho a agradecer pela professora que tem uma competência inquestionável no que faz e a todos que puderam me ajudar.

O relato apresentado evidencia a o esforço da estudante em manter-se em atividade de estudo (LEONTIEV, 1983) durante o período pandêmico - 1. semestre de 2020 - e dos processos colaborativos no movimento de ensino e aprendizagem conceitual na disciplina no curso de graduação. Identificam-se expressões que valorizam o apoio recíproco entre os participantes, esclarecendo dúvidas, tornando compreensíveis conceitos teóricos complexos que num estudo individualizado tornar-se-ia mais difícil a compreensão e a aprendizagem conceitual. A conduta colaborativa (BERNARDES, 2012) aproxima os participantes da disciplina, ainda que fisicamente estejam distantes, contribui para a percepção de integração e de respeito recíproco diante das necessidades individuais e coletivas.

Outra questão a ser ressaltada no relato é a consciência da estudante sobre a aprendizagem conceitual que gerou transformações no seu modo de pensar a educação e criou um campo favorável ao desenvolvimento pessoal. Tal fato não ocorre de forma espontânea, mas a consciência da própria transformação ocorre a partir da consciência que o ensino devidamente organizado pode promover transformações na consciência de todos os participantes da atividade pedagógica- estudantes, monitora e docente (BERNARDES, 2012). Ainda que o conhecimento teórico mediado fosse complexo e historicamente problematizado, a estudante, que aqui representa o coletivo na disciplina, valoriza a importância do conhecimento e a preservação da qualidade do ensino, assim como de todo o sistema de apoio e colaboração que garantisse efetivamente condições afetiva e cognitiva para a aprendizagem conceitual. Trata-se da objetivação do sistema de ações e operações na 


\section{Desdobramentos da pandemia Covid - 19 na educação formal: uma análise da unidade afeto-cognição}

atividade pedagógica no ensino superior, conforme explicitado anteriormente neste mesmo texto.

\section{Por uma educação necessária...}

A dimensão do drama humano é evidenciada no relato apresentado, exemplificando a situação caótica vivenciada pelos estudantes no momento de pandemia ocorrido em 2020 e evidencia aspectos fundamentais que remetem à unidade afeto-cognição na atividade pedagógica. No entanto, temos que salientar que, de acordo com Vigotski (2000), o drama humano faz parte dos processos de transformação das funções psíquicas superiores em qualquer situação que envolva processos educativos que mobilizem a unidade cognitivoafetiva.

O drama humano assume dupla objetivação no enfoque histórico-cultural; o que diz respeito às transformações internas - na perspectiva intrapsíquica quando há mudanças no sistema interfuncional; e o que diz respeito ao drama humano emergente da sociedade espetacularizada a partir das diferenças sociais. Ambos compõem as condições concretas que articulam os processos de formação e desenvolvimento psíquico. Conforme salienta Vigotski (2000, p. 35), “a dinâmica da personalidade é o drama", ou seja, trata-se das lutas internas e externas mobilizadoras de transformação da consciência e da personalidade.

O relato do drama vivido pela estudante identifica transformações resultantes do processo de estudo de um objeto complexo - objeto real e historicamente elaborado - e da adequação necessária em função do momento de crise social vivenciado no ano de 2020. Trata-se da dupla objetivação do drama vivido pelos estudantes que integraram a atividade pedagógica.

Defendemos neste artigo, portanto, que o drama vivido pelos sujeitos em atividade de estudo envolve a unidade afetivo-cognitiva que mobiliza o desenvolvimento do sistema interfuncional, independente das crises sociais historicamente instituídas, mas ao mesmo tempo as condições concretas são mobilizadoras do agravamento ou acirramento das crises pessoais. Também defendemos que a organização do ensino deve assumir princípios generalizáveis conforme identificados no sistema de ações na atividade pedagógica independentemente das crises sociais e das tecnologias implantadas na organização do ensino - seja ele presencial ou remoto. Diz respeito às condições necessárias para que o 


\section{Desdobramentos da pandemia Covid - 19 na educação formal: uma análise da}

\section{unidade afeto-cognição}

ensino devidamente organizado possa ser promotor do desenvolvimento do sistema interfuncional.

Defendemos ainda a necessidade de nos dedicarmos ao estudo aprofundado sobre o uso de tecnologias diferenciadas na organização do ensino, uma vez que as situações de crise social e pessoal não se apartarão do drama da humanidade. Consideramos ser necessário desenvolver a semente/tecnologia voltada para que o produto/educação seja eficaz e promotor do desenvolvimento humano. Tal problema é emergente, uma vez que as mudanças na organização social e nos processos educativos- principalmente no âmbito do ensino superior- dão indícios que serão duradouros.

Parafraseando Mill (2012), que as sementes germinem, que o produto seja compartilhado, que os agricultores sejam conscientes de suas funções sociais, que a democracia seja vigorosa e que a educação para todos seja uma realidade na sociedade brasileira. Essa é a nossa esperança ...

\section{Referências}

ALVARENGA, F. ; PARREIRA, M. Comissão da Câmara faz relatório com críticas à atuação do Ministério da Educação durante a pandemia. Disponível em:

https://g1.globo.com/educacao/noticia/2020/06/17/comissao-da-camara-faz-relatorio-comcriticas-a-atuacao-do-ministerio-da-educacao-durante-a-pandemia.ghtml Acesso em: 28 de jul. de 2020 .

BATISTÃO, S. P. S. Educação inclusiva ou educação para todos? - contribuições da teoria histórico-cultural para uma análise crítica da realidade escolar. 2013. Dissertação (Mestrado) - Universidade de São Paulo, São Paulo, 2013.

BEATÓN, G. A. La persona enel enfoque histórico cultural. São Paulo: Linear B, 2005.

BERNARDES, M. E. M. Ensino e aprendizagem como unidade dialética na atividade pedagógica. Psicol. Esc. Educ. (Impr.) [online]. 2009, vol.13, n.2, pp.235-242.

BERNARDES, M. E. M. Mediações simbólicas na atividade pedagógica: contribuições da Teoria Histórico-Cultural para o ensino e a aprendizagem. Curitiba: CRV, 2012.

BERNARDES, M. E. M. Modos de ação na atividade pedagógica: uma proposição de ensino e aprendizagem ativos. PBL 2010 Congresso Internacional. São Paulo, Brasil, 812 de fevereiro de 2010.

BRASIL. Constituição da República Federativa do Brasil de 1988, Brasília, DF. 
Desdobramentos da pandemia Covid - 19 na educação formal: uma análise da unidade afeto-cognição

BRASIL. Lei Federal n. 9.394, de 20 de dezembro de 1996. Estabelece as diretrizes e bases da educação nacional. Brasília. Diário Oficial da União, 1996.

BRASIL. Parecer n. 17, de 3 de julho de 2001. Diretrizes nacionais para a educação especial na educação básica. Brasília: MEC/SEESP, 2001.

BRASIL. Política nacional de educação especial na perspectiva da educação inclusiva. Brasília: MEC/SEESP, 2008.

BUENO, J. G. S. Função social da escola e organização do trabalho pedagógico. Educar em Revista. Curitiba: Universidade Federal do Paraná, 2001, n. 17, p. 101-110.

CARDOSO, C. A.; FERREIRA, V. A.; BARBOSA, F. C. G. (Des)igualdade de acesso à educação em tempos de pandemia: uma análise do acesso às tecnologias e das alternativas de ensino remoto. Revista Com Censo: Estudos Educacionais do Distrito Federal, [S.1.], v. 7, n. 3, p. 38-46, ago. 2020.

DEBORD, G. Sociedade do espetáculo. eBooksBrasil.com, 2003. Disponível em: https://a36b27e2-7d86-45f4-b828d8b03593f647.filesusr.com/ugd/dcac6b_453c47d2871a4f0a8eeee0a1ddc7bc89.pdfAcesso em: 5 de jul. 2020.

DUARTE, N. A pedagogia histórico-crítica e a formação da individualidade para si.

Germinal: Marxismo e Educação em Debate, Salvador, v. 5, n. 2, p. 59-72, dez. 2013.

ELKONIN, D. B. Epílogo. In: VYGOTSKY, L. S. Obras escogidasIV: Psicología infantil. Madrid: Visor, 1996. p. 387- 421.

ESCOBAR, H. A ciência contra o negacionismo: cientistas ganham espaço nas redes sociais, mas ainda é preciso crescer muito para superar a influência de grupos obscurantistas. Jornal da USP. Disponível em: <https://jornal.usp.br/ciencias/a-cienciacontra-o-negacionismo/>. Acesso em 7 de jun. 2021.

GUZZO, R. S. L. et al. Psicologia e Educação no Brasil: uma visão da história e possibilidades nessa relação. Psic.: Teor. e Pesq.[online]. 2010, vol.26, n.spe, pp. 131141.

HELLER, A. O cotidiano e a história.8. ed. São Paulo: Paz e Terra, 2008.

INEE - INTER-AGENCY NETWORK FOR EDUCATION IN EMERGENCIES, THEIRWORLD E A RIGHT TO EDUCATION INITIATIVE -. Requisitos mínimos para a educação em situação de emergência, crises crónicas e reconstrução. Tradução Gabinete de Estudos para a Educação e o Desenvolvimento. Escola Superior de Educação de Viana do Castelo, Programa Educar sem Fronteiras, Portugal, 2006. Disponível em http://internacional.ipvc.pt/sites/default/files/livro_INEE_MSEE_PT.pdf. Acesso em 12 jan. 2021. 
Desdobramentos da pandemia Covid - 19 na educação formal: uma análise da unidade afeto-cognição

LEONTIEV, A. N. Los motivos, las emociones y lapersonalidad. In: Actividad, conciencia, personalid. Ciudaddel Habana: Editorial Pueblo y educación, 1983.

LESSA, S. Trabalho e luta de classes na "sociedade do conhecimento". In: JIMENEZ, S.; de OLIVEIRA, J. L.; SANTOS, D. (orgs) Marxismo, Educação e Luta de Classes. ABEU: Ceará, 2010.

LIBÂNEO, J.C. Formação de Professores e Didática para Desenvolvimento Humano. Educ. Real., Porto Alegre, v. 40, n. 2, p. 629-650, 2015.

LOPES, M. A. C. Professores interlocutores e educação de surdos: a inclusão na rede estadual paulista. Revista Brasileira de Educação Especial, v. 23, n. 4, p. 563-576, 2017.

MARX, K.; ENGELS, F. Ideologia alemã. São Paulo: Expressão Popular, 2009.

MÉSZÁROS, I. A educação para além do capital. 2. ed. São Paulo: Boitempo, 2008.

MILL, D. Mudanças de mentalidade sobre educação e tecnologia. In: MILL, D. Escritos sobre educação e tecnologias emergentes: desafios e possibilidades para ensinar e aprender na contemporaneidade. São Paulo: Paulus, p. 11-38, 2012.

MOURA D. H; LIMA FILHO D. L.; SILVA M. B., 2015. Politecnia e formação integrada: confrontos conceituais, projetos políticos e contradições históricas da educação brasileira. Revista Brasileira de Educação v. 20 n. 63 out.-dez. 2015. p.1057-1080.

PEREIRA, E. C. Os processos formativos do professor de alunos com Transtorno do Espectro Autista: contribuições da Teoria Histórico-Cultural. 2016. Dissertação (Mestrado em Educação) - Faculdade de Educação, Universidade de São Paulo, São Paulo, 2016.

PPGED- UFSCAR. Relatório de pesquisa: Condições e dinâmica cotidiana e educativa na RMS (Região Metropolitana de Sorocaba/SP) durante o afastamento social provocado pelo Coronavírus. PPGEd-So - Programa de Pós-Graduação em Educação da UFSCar Campus Sorocaba, Sorocaba/SP, maio de 2020. Disponível em:

http://www.ppged.ufscar.br/ptbr/arquivos-1/relatorio-de-pesquisa-educacao-e-coronavirusna-reg-de-sorocaba-ufscar-26- 05-2020pdf.pdf. Acesso em: 13 jun 2020.

POLITZER, G. Crítica dos fundamentos da psicologia: a psicologia e a psicanálise. Piracicaba, SP: Editora UNIMEP, 1998.

SAMPAIO, M. M. F. Um gosto amargo de escola: relação entre currículo, ensino e fracasso escolar. São Paulo: EDUC, 1998.

SANTOS, J. S. Pandemia evidencia a emergência de superar o capitalismo e conceber outro socialismo.Entrevista especial com Luiz Marques. Instituto Humanas Unisinos. Disponivel em: http://www.ihu.unisinos.br/601328-pandemia-evidencia-a-emergencia-desuperar-o-capitalismo-e-conceber-outro-socialismo-entrevista-especial-com-luiz- 
Desdobramentos da pandemia Covid - 19 na educação formal: uma análise da unidade afeto-cognição

marques?fbclid=IwAR3TOJsPOpKB6HoDHAXTfBVv-

ELHIwnrPXKygwm5tmOxr4AEuhyvaUaoTjc Acesso em: 29 de jul. de 2020.

SAVIANI, D. Pedagogia histórico-crítica: primeiras aproximações. 11. ed. Campinas: Autores Associados, 2013.

SILVA, P. A.; GODOY, E. A. Educação a distância em tempos de pandemia: faces das desigualdades sociais preexistentes. Anais do Congresso Internacional de Educação e Tecnologias - Encontro de Pesquisadores em Educação a Distância, São Carlos, ago. 2020.

SOUZA, R. M. Q; COUTO, J. C. D; COUTO, L. S. M. D. Escolas e a pandemia, ações de enfrentamento do afastamento educacional: uma investigação sobre as escolas durante o isolamento provocado pelo coronavírus no período de março a maio 2020, na baixada santista. Cadernos CERU, Série 2, Vol. 31, n. 1, jun. 2020. Disponível em: https://www.revistas.usp.br/ceru/article/download/174488/163252/433000. Acesso em 13 jun. 2021.

STEVANIM, L. F. Exclusão nada remota: desigualdades sociais e digitais dificultam a garantia do direito à educação na pandemia. RADIS: Comunicação e Saúde, n. 215, p. 10 15, ago. 2020.

TANAMACHI, E. de R.; MEIRA, M. E. M. A atuação do psicólogo como expressão do pensamento crítico em psicologia e educação. In: MEIRA, M. E. M.; ANTUNES, M. A. M. Psicologia escolar: práticas críticas. São Paulo: Casa do Psicólogo, 2003. p. 11-62.

TONET, I. Atividades educativas emancipadoras. Rev. Práxis Educativa.Vol. 9, n. 1, p.924, 2014.

UNESCO. Declaração de Salamanca. Organização das Nações Unidas para a Educação, a Ciência e a Cultura. Salamanca, Espanha, 7 - 10 de junho de 1994. Editado pela Unesco.

UNESCO. Education in emergencies. Disponível em:

https://en.unesco.org/themes/educationemergencies\#: :text=UNESCO $\% 20$ helps\%20strengthen $\% 20$ education $\% 20$ systems, and $\% 2$ 0psychological\%20safety\%20to\%20children. Acesso em 12 jan. 2021.

UNESCO. Declaração mundial sobre educação para todos: satisfação das necessidades básicas na aprendizagem. Jomtien, 1990. Editado pela Unesco, 1998.

VÁSQUEZ, A. S. Filosofia da práxis. 2. ed. Filosofia da práxis Rio de Janeiro: Paz e Terra, 1977.

VYGOTSKI, L. S. A construção do pensamento e da linguagem. São Paulo: Martins Fontes, 2001.

VYGOTSKI. Sobre los sistemas psicológicos. In: VYGOTSKI, L. S. Obras escogidas I.2a ed. Madrid: Visor Dis. SA., 1997a. 
Desdobramentos da pandemia Covid - 19 na educação formal: uma análise da unidade afeto-cognição

VYGOTSKI. El problema del retraso mental. In: VYGOTSKI, L. S. Obras escogidas V.2a ed. Madrid: Visor Dis. SA., 1997b.

VYGOTSKI. La crisis de lossieteaños. In: VYGOTSKI, L. S. Obras escogidas IV.2a ed. Madrid: Visor Dis. SA., 2006.

VYGOTSKI. Manuscrito de 1929.Educ. Soc., Campinas, v. 21, n. 71, p. 21-44, July 2000. Disponível em: http://www.scielo.br/scielo.php?script=sci_arttext\&pid=S0101$73302000000200002 \& \operatorname{lng}=$ en\&nrm=iso. Acesso em 05 jul 2020.

VYGOTSKI. Teoría de las emociones: Estudio histórico-psicológico. Ediciones Akal S. A., Madrid, Espanha, 2004.

VYGOTSKI VYGOTSKI. Teoria e método em psicologia. São Paulo: Martins Fontes, 1996. 